\title{
Effect of nitric oxide synthase inhibitors on ovum transport and oviductal smooth muscle activity in the rat oviduct
}

\author{
S. Perez Martinez ${ }^{1}$, M. Viggiano ${ }^{1}$, A. M. Franchi ${ }^{1}$, M. B. Herrero ${ }^{1}$, M. E. Ortiz ${ }^{2}$, M. F. Gimeno ${ }^{1}$ \\ and M. Villalón ${ }^{2}$ \\ ${ }^{1}$ Centro de Estudios Farmacológicos y Botánicos (CEFYBO-CONICET), Serrano 669, Buenos Aires, Argentina; and ${ }^{2}$ Unit of \\ Reproduction and Development, Pontificia Universidad Católica de Chile, Santiago de Chile, Chile
}

\begin{abstract}
The effect of the inhibition of nitric oxide synthase (NOS) on ovum transport and oviductal motility in rats was investigated. Three different NOS inhibitors were injected into the ovarian bursa at oestrus or day 3 of pregnancy. Oviducts and uteri were flushed $24 \mathrm{~h}$ later and the presence of ova was recorded. In oestrous and pregnant rats, treatment resulted in accelerated egg transport, as shown by a decrease in the number of ova present in the oviducts. In cyclic rats, intrabursal injection of $1 \mathrm{mg} \mathrm{kg}^{-1}$ of either $\mathrm{N}$-monomethyl-L-arginine (L-NMMA) or $\mathrm{N}^{\omega}$ nitro-L-arginine methyl ester (L-NAME) elicited a $30 \%$ reduction in the number of ova present in the oviducts, whereas in pregnant animals, the same dose of L-NMMA produced a reduction of $40 \%$. Simultaneous administration of the NO donor spermine NONOate $\left(5 \mathrm{mg} \mathrm{kg}^{-1}\right)$ completely reversed the effect of L-NMMA. Tubal motility was assessed by microsphere displacement analysis within the oviduct. Surrogate ova were transferred to the oviductal lumen at oestrus and $24 \mathrm{~h}$ later the effect of intraoviductal injection of $1 \mu \mathrm{g} \mathrm{L}$ NMMA or vehicle was assessed. The microspheres in the isthmus showed an oscillating motion, and periods in which movement was not detectable. However, L-NMMA treatment produced a 3.6-fold increase in the maximum instant velocities and a significant reduction in the resting periods of the microspheres compared with the control group $(P<0.001)$. These results provide evidence that NO inhibition increases tubal motility that results in accelerated ovum transport, and indicate that $\mathrm{NO}$ could act as a paracrine signal between different layers of the oviductal wall, providing a role for endogenous NO in regulation of tubal function.
\end{abstract}

\section{Introduction}

Gamete and embryo transport in the mammalian oviduct results from a complex and still poorly understood interaction of smooth muscle contractions, ciliary activity and secretory function. Regulation of ovum transport in mammals appears to be dependent on different factors, including ovarian hormones: endogenous steroid hormones regulate the passage of ova from the oviduct to the uterus in rats (Croxatto et al., 1991). However, early hamster embryos produce factors such as $\mathrm{PGE}_{2}$ and platelet activating factor (PAF) that might regulate their transport towards the uterus (Hermoso et al., 1996). It is not clear how all these factors can influence the tubal mechanical effectors that generate the forces that promote the movement of gametes and zygotes in the oviduct.

Nitric oxide (NO) has been implicated in events associated with a variety of female reproductive functions, such as

Received 18 February 1999. ovulation (Shukovski and Tsafriri, 1994; Bonello et al., 1996), steroidogenesis (Van Voorhis et al., 1994), follicle survival (Chun et al., 1995) and maintenance and termination of pregnancy (Conrad et al., 1993; Yalampalli et al., 1993, 1994a,b). Furthermore, NO synthase (NOS) has been found in the mammalian oviduct and several effects of $\mathrm{NO}$ on oviductal smooth muscle contractions have been described. Ekerhovd et al. (1997) found that NO plays a role as a relaxing agent in human oviducts; Rosselli et al. (1994) reported that $\mathrm{N}^{\omega}$ nitro-L-arginine methyl ester (L-NAME), a NOS inhibitor, enhanced the contractile effect of endothelin 1. Different NOS isoforms have been found in the rat oviduct (Perez Martinez et al., 1997) and PGF ${ }_{2 \alpha}$ and NO are involved in the regulation of rat oviductal motility (Perez Martinez et al., 1998).

In view of these findings, the aim of this study was to establish whether the administration of NOS inhibitors during the oestrous cycle and early pregnancy can modify oviductal transport in the rat and to determine whether this effect is mediated by changes in oviductal motility. 


\section{Materials and Methods}

\section{Chemicals}

The NOS inhibitors N-monomethyl-L-arginine (L-NMMA), $N$-monomethyl-D-arginine (D-NMMA), $\mathrm{N}^{\omega}$ nitro-L-arginine methyl ester (L-NAME), $\mathrm{N}^{\omega}$ nitro-D-arginine methyl ester (DNAME) and L-nitro arginine ( $\mathrm{NO}_{2}$-Arg) were purchased from Sigma Chemical (St Louis, MO). Spermine NONOate was obtained from Cayman Chemical (Ann Arbor, MI).

\section{Animals and treatment}

Adult female Wistar rats (200 g) were housed under controlled lighting conditions of $14 \mathrm{~h}$ light: $10 \mathrm{~h}$ dark and food and water were available ad libitum.

Vaginal cytology was monitored once a day and only animals showing a regular 4 day oestrous cycle for more than two cycles were used. Rats were assigned at random to one of two groups: pregnant and cyclic rats. Females assigned to the pregnant group were caged with males of proven fertility in the evening of proestrus, and mating was verified by observation of spermatozoa in the vaginal smear on the following morning. Cyclic animals were not caged with males. The day after proestrus was designated as day 1 of pregnancy or day 1 of the oestrous cycle.

\section{Assessment of transport}

These experiments were designed to study the effect of NOS inhibitors on ovum transport both in cyclic and pregnant rats. At 13:00 h on day 1 of the oestrous cycle or day 3 of pregnancy, rats were anaesthetized and their ovaries were exposed through a dorsal incision. NOS inhibitors (or their inactive enantiomers) were administered as a single intrabursal (i.b.) injection, dissolved in $25 \mu$ l saline solution (vehicle). Control animals received the vehicle alone. Incisions were sutured and the animals were allowed to rest until the next day. At $24 \mathrm{~h}$ after treatment the rats were killed and oviducts and uteri were removed, dissected free of fat tissue, and transected at the uterotubal junction. The oviducts and uteri were flushed separately as described by Ortiz et al. (1979). All flushings were examined under low power magnification to identify the ova. The number of ova recovered from each segment was recorded. A total of 72 cyclic and 36 pregnant rats were used in these experiments; five to nine rats were used for each experimental treatment.

The rats were treated on day 3 of pregnancy on the basis of studies indicating that the sensitivity of the oviduct to factors that accelerate egg transport is increased on this day of pregnancy. Ortiz et al. (1994) reported an increased ability of the organ to accumulate oestradiol on day 3 . This finding was related to the need to ensure passage of morulae into the uterus or to the fact that the ova on day 3 are much closer to the uterus than at the earlier stages of pregnancy.

\section{Transfer of microspheres to the oviduct}

Dextran blue microspheres of $80-120 \mu \mathrm{m}$ in diameter (Density Marker Beads; Pharmacia, Uppsala) were transferred to the rat oviductal lumen at 10:00 h on day 1 of the oestrous cycle according to the technique described by Moore and Croxatto (1988a). Briefly, rats were anaesthetized with ether and four to six microspheres were injected into each oviduct using a microsyringe, through flank incisions to expose the genital tract. Transfers were performed under a surgical microscope. After $24 \mathrm{~h}$ (that is at 10:00 h on day 2 of the oestrous cycle), the animals were separated into two groups: one group of rats was injected with $2 \mu \mathrm{l}$ (1 $\mu$ g per rat) L-NMMA into the oviduct and the other group was injected with saline solution (control).

\section{Assessment of microsphere transport}

Immediately after the injection of L-NMMA or saline, movement of dextran blue microspheres was observed and recorded in situ, under ether anaesthesia. For this purpose, oviducts (isthmic segment) were exposed through the same incision used to transfer the microspheres. The observation period did not exceed $120 \mathrm{~min}$ and the temperature and moisture of the organs exposed were maintained approximately constant with the aid of a lamp and frequent irrigation with warm saline solution. The movements of the microspheres were recorded using a digital video camera Sony Hi 8 mm (Model CCD-V5000); videotaping began 30 min after the injection of L-NMMA or saline. Single video image frames were transferred to a computer Leading Edge (model 386x) equipped with an image frame grabber (Data Translation 2856) and the software Imagepro (Media Cybernetics, Silver Springs, MD). Digital image analysis of the videotapes (recorded at 30 frames $\mathrm{s}^{-1}$ ) was used to measure the distance travelled by each microsphere and instant transport velocities were calculated. The following convention was adopted to distinguish the direction of displacement: transport velocities were considered positive when the ova moved towards the uterine end of the oviduct and negative when ova moved towards the ovarian end. Ten rats were observed and 60-90 movements were recorded for each rat.

\section{Statistical analysis}

Results from the different experimental treatments were analysed using Model I ANOVA; F test was used for comparisons of variances and comparisons between groups were made using Student-Newman-Keuls test. Descriptive statistics of Gaussian curves was performed according to Sokal and Rohlf (1981).

\section{Results}

\section{Effect of NOS inhibition on ovum/ova transport}

In this experiment, the effect of NOS inhibitors injected into the ovarian bursae was assessed by observing the numbers of ova retained in the oviduct. Croxatto and Villalón (1994) described the passage of ova from the oviduct 
to the uterus in rats. In cyclic rats, approximately 12 oocytes enter the oviduct during oestrus and remain there until the next pro-oestrus. At this stage, the number of ova in the oviduct is reduced as they pass to the uterus. In pregnant rats, the passage of embryos to the uterus occurs between the night of day 4 and the morning of day 5 of pregnancy. In the present study there was a statistically significant reduction in the number of ova present in the oviducts in the experimental groups compared with the controls, indicating ovum transport was accelerated in the treated animals.

\section{Oestrous cycle}

In a preliminary experiment, three different NOS inhibitors (L-NMMA, L-NAME and $\mathrm{NO}_{2}$-Arg) accelerated ovum transport in cyclic rats. Intrabursal injection of $1 \mathrm{mg}$ $\mathrm{kg}^{-1}$ (0.1 mg per bursa) of L-NMMA or L-NAME elicited a $30 \%$ reduction of the number of ova present in the oviduct, whereas $\mathrm{NO}_{2}$-Arg produced a $42 \%$ reduction (Fig. 1 ).

A dose-response curve was constructed for L-NAME. The maximum effect (55\%) was attained with $10 \mathrm{mg} \mathrm{kg}^{-1}(1 \mathrm{mg}$ per bursa), whereas the same dose of the inactive enantiomer D-NAME exerted no effect (Fig. 2).

Ovum transport appeared to be more sensitive to LNMMA (Fig. 3). Treatment with a dose of $0.1 \mathrm{mg} \mathrm{kg}^{-1}(0.01$ $\mathrm{mg}$ per bursa) caused a $54 \%$ decrease in the number of ova in oviductal flushings. However, when L-NMMA concentration was increased to $10 \mathrm{mg} \mathrm{kg}^{-1}$, no further inhibition was observed. In this experiment, no oocytes could be found in uterine flushings.

\section{Early pregnancy}

A possible role of $\mathrm{NO}$ in the regulation of ovum transport was examined in pregnant rats using L-NMMA, which was

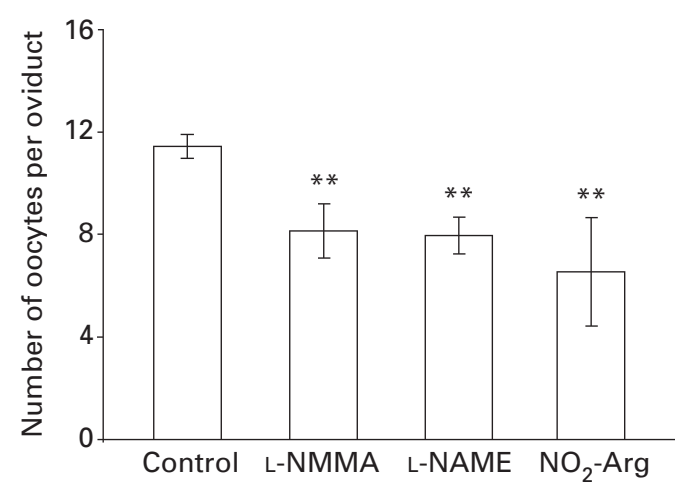

Fig. 1. Effect of three different nitric oxide synthase (NOS) inhibitors (L-NMMA, L-NAME and $\mathrm{NO}_{2}$-Arg) on oviductal transport in cyclic rats. The animals were administered an intrabursal (i.b.) injection of saline solution (control) or $1 \mathrm{mg} \mathrm{kg}^{-1}$ of inhibitor and $24 \mathrm{~h}$ later oocytes were counted in oviductal and uterine flushings. Oocytes were recovered only from the oviductal flushings. Bars show mean \pm SEM of oocyte counts from the oviducts of six to nine rats. L-NMMA: $\mathrm{N}$-monomethyl-L-arginine; L-NAME: $\mathrm{N}^{\omega}$ nitro-L-arginine methyl ester; $\mathrm{NO}_{2}$-Arg: L-nitro arginine. ${ }^{*} P<0.01$, treatment versus control.

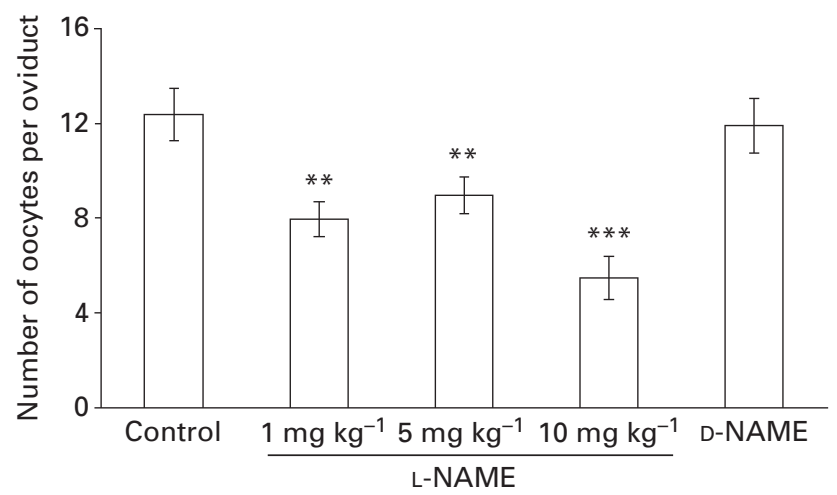

Fig. 2. Mean number of ova per animal recovered from oviductal flushing of cyclic rats at $24 \mathrm{~h}$ after an intrabursal (i.b.) injection of different concentrations of $\mathrm{N}^{\omega}$ nitro-L-arginine methyl ester (LNAME) or its inactive enantiomer (D-NAME). Treatment was given on the day of oestrus. Bars show mean \pm SEM of oocyte counts from the oviducts of six to nine rats. ${ }^{* *} P<0.01,{ }^{* * *} P<0.001$, treatment versus control.

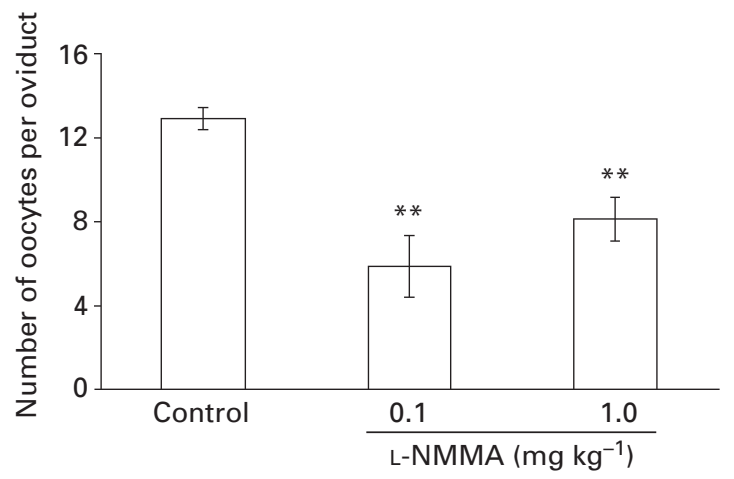

Fig. 3. Mean number of oocytes recovered from rat oviductal flushings $24 \mathrm{~h}$ after an intrabursal (i.b.) injection of saline solution (control) or the nitric oxide synthase (NOS) inhibitor $\mathrm{N}$ monomethyl-L-arginine (L-NMMA) administered on the day of oestrus. Bars show mean \pm SEM of oocyte counts from the oviducts of six to nine rats. ${ }^{* *} P<0.01$, treatment versus control.

the most potent inhibitor under the experimental conditions in the present study. A dose-response curve $(0.01-1.0 \mathrm{mg}$ $\mathrm{kg}^{-1}$ ) was constructed for L-NMMA (Fig. 4). Both 0.1 and 1.0 $\mathrm{mg} \mathrm{kg}^{-1}$ doses reduced the number of ova in the oviduct when injected inside the ovarian bursa on day 3 of pregnancy ( $33 \%$ and $40 \%$, respectively) (Fig. 4). In this experiment, the effect of an NO donor, spermine NONOate, was tested. Spermine NONOate alone $\left(5 \mathrm{mg} \mathrm{kg}^{-1}\right)$ did not alter egg transport, but completely reversed the effect of L-NMMA.The specificity of the effect of L-NMMA was confirmed by using the inactive enantiomer D-NMMA. All the embryos found in oviductal flushings were at the morula stage. In approximately $20 \%$ of the animals, a number of embryos could be recovered from uterine flushings (Fig. 4); these embryos were also at the morula stage. 


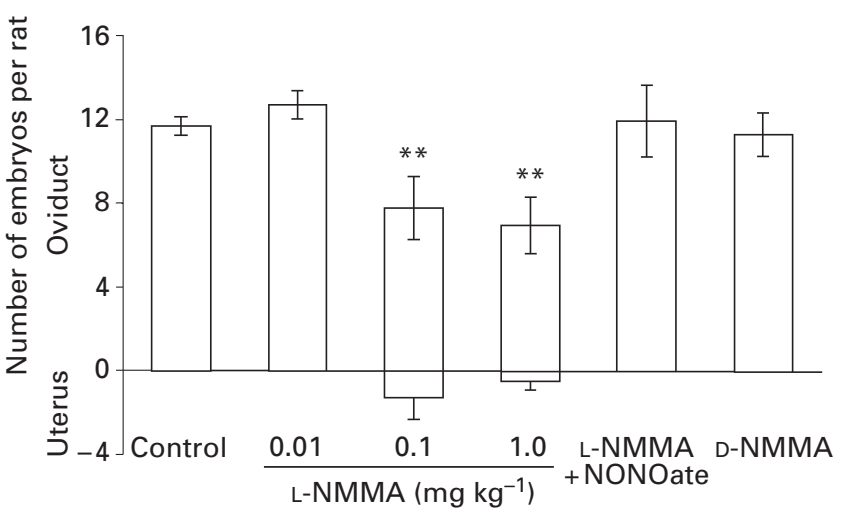

Fig. 4. Effect of N-monomethyl-L-arginine (L-NMMA) on embryo transport in rats. Females on day 3 of pregnancy were given an intrabursal (i.b.) injection of different doses of L-NMMA. The animals were killed $24 \mathrm{~h}$ after the injection and the oviducts and uteri were flushed with saline solution to determine the number of embryos in each segment. L-NMMA accelerated embryo transport. The effect of L-NMMA was completely blocked by simultaneous administration of an NO donor, spermine NONOate $\left(5 \mathrm{mg} \mathrm{kg}^{-1}\right)$. The inactive enantiomer D-NMMA $\left(1 \mathrm{mg} \mathrm{kg}^{-1}\right)$ of the NOS inhibitor did not alter egg transport. Normal embryos at the morula stage were recovered in these two groups. Bars show the mean \pm SEM of oocyte counts from the oviduct or the uterus of six rats. ${ }^{* *} P<0.01$, treatment versus control.

\section{Microsphere transport}

Microspheres were transferred to the oviductal lumen at oestrus and $24 \mathrm{~h}$ later the effect of intraoviductal injection of $1 \mu \mathrm{g}$ L-NMMA was assessed. At this time, microspheres were found in the isthmus.

In control and experimental groups, transport of dextran blue microspheres in the isthmus of the rats showed a typical oscillating motion, towards both the ovary and uterus, and periods of rest or undetectable movement. A sequence of images of microsphere displacement and the corresponding period of elapsed time (s) for control and treated groups is presented (Fig. 5).

Calculated instant average velocities (Table 1) showed no statistical differences between groups; mean velocity values ranged between 29.8 and $113.1 \mu \mathrm{m} \mathrm{s}^{-1}$. Maximum instant velocities of 8457 and $2300 \mu \mathrm{m} \mathrm{s}^{-1}$ were measured in $\mathrm{L}^{-}$ NMMA-treated and control animals, respectively, indicating a 3.6-fold increase in L-NMMA-treated animals compared with the controls.

The frequency distribution of calculated instant velocities for each group is shown (Fig. 6). The two groups showed a normal distribution, centred at zero velocity (mode $=0$ ), indicating the random direction of movement towards the uterus or the ovary. L-NMMA treatment produced a significant $(P<0.001)$ increase in the range (variance) of maximum instant velocity. In addition, the treated group showed a significant decrease in resting periods (instant velocity $\left.=0 \mu \mathrm{m} \mathrm{s}^{-1}\right)$ compared with the control group $(5 \%$ and $20 \%$, respectively; $P<0.001$ ).

Table 1. Summary of statistical analysis of instant velocity measurements of microsphere displacement in the rat oviduct

\begin{tabular}{lccc}
\hline & Control & L-NMMA & $P$ value \\
\hline Mean* & 29.8 & 113.1 & ns \\
SD $^{*}$ & 24.9 & 94.3 & $<0.001$ \\
$n$ & 393 & 476 & \\
Range & -2027 to 2300 & -7268 to 8457 & \\
Mode & 0 & 0 & \\
\hline
\end{tabular}

*Mean and standard deviation (SD) of instant velocities are expressed in $\mu \mathrm{m} \mathrm{s}^{-1}$ L-NMMA: N-monomethyl-L-arginine.
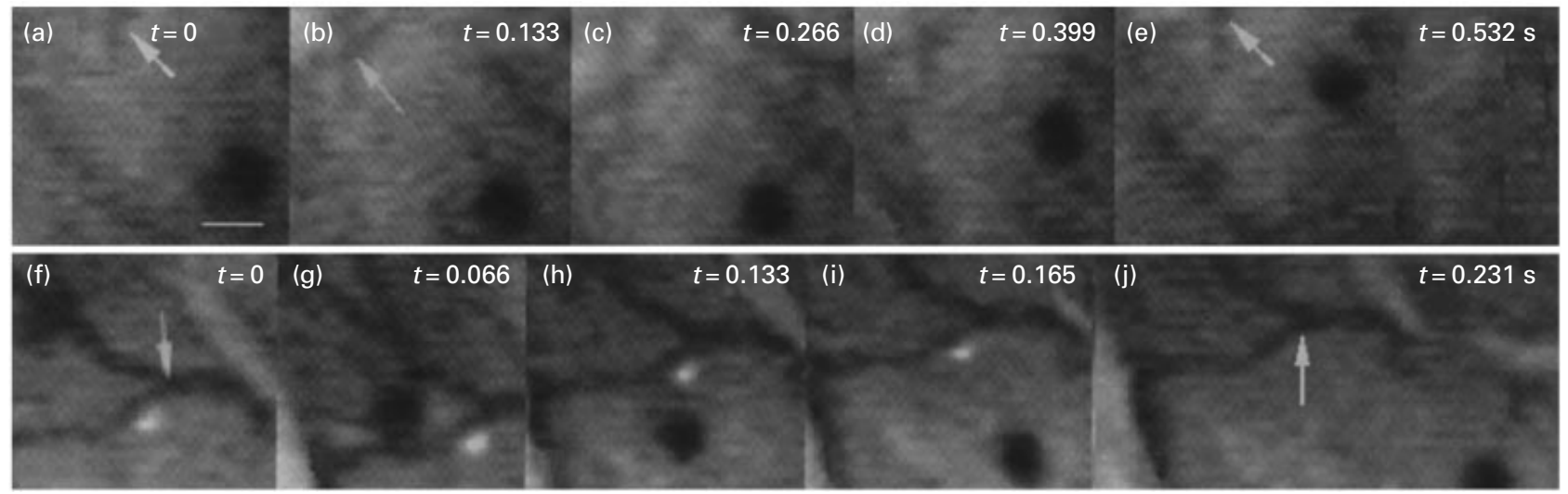

Fig. 5. Photomicrographs showing dextran blue microsphere displacement in the rat oviduct. Arrows show the capillary vein as a reference point. Control sequence (a-e) represents $0.532 \mathrm{~s}$ of recording, and shows the microsphere travelling towards the reference point, a distance of $117 \mu \mathrm{m}$ from right to left, at a calculated instant velocity of $220 \mu \mathrm{m} \mathrm{s}^{-1}$. The $N$-monomethyl-L-arginine (L-NMMA; $1 \mu \mathrm{g}$ per rat) sequence (f-j) represents $0.231 \mathrm{~s}$. During this time, the microsphere moved $667 \mu \mathrm{m}$, from left to right, at a calculated instant velocity of $2886 \mu \mathrm{m} \mathrm{s}{ }^{-1}$. Scale bar represents $100 \mu \mathrm{m}$. 


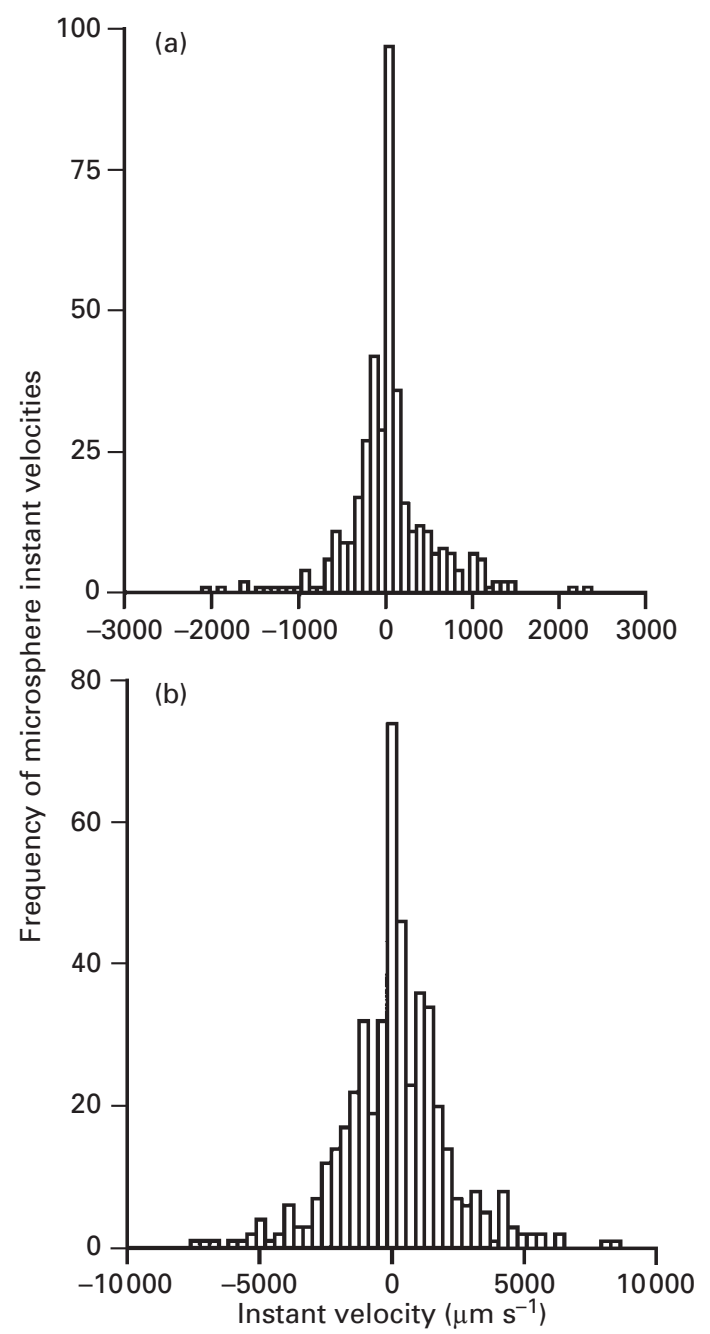

Fig. 6. Frequency distribution of calculated instant velocities of microsphere displacements in the rat oviduct in (a) control and (b) $\mathrm{N}$-monomethyl-L-arginine (L-NMMA)-treated animals ( $1 \mu \mathrm{g}$ per rat). Details of instant velocity measurements are as described in Fig. 5. Both groups show a normal distribution, centred at zero velocity (mode $=0$ ), indicating the random direction of movement towards the uterus or the ovary. L-NMMA treatment produced a significant $(P<0.001)$ increase in the range (variance) of maximum instant velocity.

\section{Discussion}

This work demonstrates that local administration of different NOS inhibitors significantly increased oviductal transport of ova in both cyclic and pregnant rats, probably by increasing oviductal motility. These results, combined with the observations that NOS is present in rat oviductal epithelium (Perez Martinez et al., 1997) and that L-NMMA increases oviductal contractions, including contractions induced by PGF $_{2 \alpha}$ (Perez Martinez et al., 1998), indicate a role for endogenous $\mathrm{NO}$ in the regulation of oviductal function in rats.

Three different and highly specific NOS inhibitors (LNAME, L-NMMA and $\mathrm{NO}_{2}$-Arg) injected in the ovarian bursa of cyclic rats produced a significant decrease in the number of ova present in the oviduct compared with salinetreated animals. L-NMMA was the most potent of the three inhibitors; treatment with a dose of $0.1 \mathrm{mg} \mathrm{kg}^{-1}$ caused a $54 \%$ decrease in the number of ova found in oviductal flushings. Doses higher than $10 \mathrm{mg}$ L-NAME $\mathrm{kg}^{-1}$ or $1 \mathrm{mg}$ L-NMMA $\mathrm{kg}^{-1}$ elicited lower responses than the maximum effect.

In pregnant rats, L-NMMA injected into the ovarian bursa on day 3 of pregnancy accelerated ovum transport (33-40\%). The specificity of the observed effects of the inhibitors, in both cyclic and pregnant rats, was confirmed when the inactive enantiomers D-NAME and D-NMMA were used and no effect on ovum transport was observed. The NO donor spermine NONOate alone did not affect ovum transport in pregnant rats; however, NONOate completely reversed the acceleration elicited by L-NMMA.

The early arrival of ova at the uterus of cyclic rats at a time when the uterus normally expels ova may explain the complete absence of oocytes in uterine flushings in this group. Dickmann and Noyes (1960) reported expulsion of ova after anticipated surgical transfer to the uterus in rats, whereas Ortiz et al. (1979) found that oestradiol administration accelerated ovum transport and expulsion of ova from the uterus. Hence, in the present study ova may have been expelled from the uterus or alternatively broken down within this organ. In pregnant rats, a number of morulae were found in the uterus as a result of the accelerated transport induced by the NOS inhibitor (LNMMA). In addition, simultaneous administration of $\mathrm{L}^{-}$ NMMA and NO donor (NONOate) did not produce an effect on early embryo development. These observations indicate that the reduction in the number of eggs was due to accelerated ovum transport rather than the breakdown of eggs in the genital tract.

Detailed measurements of the transport of supravitally stained ova within the cumulus inside the oviduct recorded by microscopic cinematography revealed that phasic muscle contractions of the oviducts are responsible for the typical random oscillating movements of ova, which have been observed in the oviduct of a variety of species, including primates (Halbert et al., 1976; Verdugo et al., 1976; Villalón et al., 1991). These oscillating motions are produced by contractions of the circular smooth muscle of the oviductal wall and indicate that myoelectric activity and the mechanical performance of the myosalpinx have a large random component (Portnow et al., 1977).

The effect of NOS inhibition was also studied by measuring oviductal transport velocities of surrogate ova to gain further support for the hypothesis that endogenous NO participates in ovum transport by regulating oviductal contractility. Microspheres transferred to the infundibulum of the rat oviduct on day 1 of pregnancy reproduce the movement of native ova without disturbing it (Moore and Croxatto, 1988a). In addition, treatment with oestradiol caused accelerated transport by increasing the frequency of the contractions of the smooth muscle of the isthmus (Moore and Croxatto, 1988b).

In the present study, in control and experimental groups, transport of dextran blue microspheres in the isthmus of rats showed the typical oscillating movement towards the 
direction of the ovary or uterus, and periods of rest or undetectable movement. The L-NMMA treatment produced maximum instant velocities, showing a 3.6-fold increase compared with maximum instant velocities in the control group. In addition, the treated group showed a lower frequency of resting periods than the control group.

The distribution of velocities in both groups followed a Gaussian curve, centred at zero, indicating the random direction of movement towards the uterus or ovary. LNMMA treatment produced a significant $(P<0.001)$ increase in the range (variance) of instant velocities, but no differences between the centre of the distribution of instant velocities in the control and experimental groups. The observed Gaussian distribution of the instant velocities of the microspheres are in agreement with a stochastic model for tubal gamete transport, in which accelerated transport can occur by changing the length or the frequency or both the length and the frequency of the pendular motions of the eggs or surrogate ova in the oviduct (Verdugo and Villalón, 1993).

There is considerable evidence supporting the hypothesis that movement of materials within the oviduct, including microspheres, is associated with electrical activity from the oviductal muscle layer (Talo, 1991; Verdugo and Villalón, 1993). The movement of microspheres is clearly associated with peristaltic contractions of the isthmus. Therefore, it is proposed that the effect on the movement of microspheres described here is dependent on smooth muscle contractions, whereas the contribution of ciliary activity to ovum transport through the isthmus is minimal or does not occur in this segment of the rat oviduct.

The relationship between ovum transport and smooth muscle contractions in the oviduct is also supported by the observation that there is a reduction in the number of ciliated cells in the luminal surface, coincident with an increase in the thickness of the smooth muscle layer, in the isthmic region of the mammalian oviduct (Woodruff and Pauerstein, 1969). Ciliary activity moves any material within the oviduct in the ovary-uterus direction (Halbert et al., 1976), and muscle contractions produce an oscillating movement that results in ovum transport towards the uterus. Thus, the synchronized effect of smooth muscle and ciliary activity ensures that embryos reach the uterus at the appropriate time for implantation (Verdugo and Villalón, 1993).

It is well established that concentrations of ovarian hormones modify tubal transport rates. In pregnant rats, oestradiol consistently accelerates the transport of ova (Ortiz et al., 1979), but this effect can be blocked by simultaneous administration of progesterone (Fuentealba et al., 1988). In addition, oestradiol induced a significant increase in connexin Cx43 (Hermoso et al., 1997), a gap junction component, in the smooth muscle layer of the rat oviduct, whereas progesterone produced the opposite effect (Villalón et al., 1997). These authors also found that oestradiol induced the highest velocities of surrogate ova, supporting the idea that synchronized muscle activity in the oviduct will be improved by the presence of gap junctions between smooth muscle cells, allowing the propagation of contraction waves for long distances and with increased force.

Uterine and oviductal NOS activity and expression have also been related to steroid hormones or the ratio of oestradiol:progesterone (Rosselli et al., 1998). In the rat uterus, progesterone controls the nitric oxide-dependent relaxation of the smooth muscle (Chwalisz and Garfield, 1994).

NO could play a role in the regulation of ovum transport by maintaining the oviductal quiescence while the oocytes or embryos are present in the tube. Before ova leave the oviduct, NOS activity and expression may decrease and therefore allow the effect of contractile molecules, such as endothelin 1 or PGF $_{2 \alpha}$ (Rosselli et al., 1994; Perez Martinez et al., 1998), to induce oviductal motility. This hypothesis is supported by the study of Chatterjee et al. (1996) who used an antibody against endothelial NOS and found maximum labelling on the epithelial layer during pro-oestrus and oestrus and minimal labelling on the other days of the oestrous cycle. They suggested that this result corresponded to a variation in NO production, which provides oviductal relaxation during pro-oestrus and oestrus to facilitate the capture, retention and fertilization of the released ova and could facilitate active transport of the fertilized oocytes to the uterus during metoestrus and dioestrus. Chwalisz et al. (1999) reported almost no effect of NOS inhibitors administered s.c. upon pregnancy outcome in rats. However, in the same study, a synergistic role of $\mathrm{NO}$ and progesterone during the establishment of pregnancy was found. The discrepancy between the results of this study and those of the present study may be explained by the fact that, in the present study, the NOS inhibitors were applied directly to the oviduct, achieving much higher doses of the drugs.

The findings of the present study indicate that NO could act as a paracrine signal between different layers of the oviductal wall, since $\mathrm{NO}$ is actively synthesized in the epithelium and exerts its action on muscle layers. This is consistent with the cardiovascular system, in which NO is produced by the endothelial cells, but exerts a paracrine effect on the smooth muscle of the vessels (Nathan, 1992).

Factors other than steroid hormones may also regulate egg transport. Hermoso et al. (1996) demonstrated that early hamster embryos produce factors, such as $\mathrm{PGE}_{2}$ and PAF, that might regulate their transport towards the uterus. Another indication that the oviduct could react to the presence of ova is provided by the differences in rat oviductal contractility and prostaglandin production in vitro when ova are present or have been removed from the lumen (Viggiano et al., 1990). In addition the early pregnancy factor $(\mathrm{EPF})$ described in the mouse and rabbit oviduct is apparently produced in response to PAF or another unidentified ovum factor secreted by fertilized oocytes (Sueoka et al., 1989). Therefore, the possibility that embryos regulate $\mathrm{NO}$ production during egg passage through the oviduct cannot be excluded.

In summary, this study is the first to demonstrate that locally injected NOS inhibitors can accelerate tubal transport in rats by increasing tubal motility. The findings indicate that $\mathrm{NO}$ could act as a paracrine signal between different layers of the oviductal wall, providing a role in the regulation of oviductal function.

This work was supported by PRE-018/PLI 30297 of PLACIRH to S. Perez Martinez, PMT-PICT-0506 of Agencia Nacional de Promoción Científica y Tecnológica to M. Viggiano, and FONDECYT grant 8980008 to M. Villalón. 


\section{References}

Bonello N, McKie K, Jasaper M, Andrew L, Ross N, Braybon E, Brännström M and Norman RJ (1996) Inhibition of nitric oxide - effects on interleukin1-beta-enhanced ovulation rate steroid hormones, and ovarian leukocyte distribution at ovulation in the rat Biology of Reproduction 54 436-445

Chatterjee S, Gangula PRR, Dong Y-L and Yallampalli C (1996) Immunocytochemical localization of nitric oxide synthase-III in reproductive organs of female rats during the oestrous cycle Histochemical Journal 28 715-723

Chun SY, Eisenhauer KM, Kubo M and Hsueh AJW (1995) Interleukin-1 $\beta$ suppresses apoptosis in rat ovarian follicles by increasing nitric oxide production Endocrinology 136 3130-3137

Chwalisz K and Garfield RE (1994) Role of progesterone during pregnancy: models of parturition and preclampsia Zeitschrift Geburtshilfe und Perinatologie 198 170-180

Chwalisz K, Winterhager E, Thienel T and Garfield RE (1999) Synergistic role of nitric oxide and progesterone during the establishment of pregnancy in the rat Human Reproduction 14 542-552

Conrad KP, Joffe GM, Kruszyna H, Kruszyna R, Rochelle LG, Smith RP, Chavez JE and Mosher MD (1993) Identification of increased nitric oxide biosynthesis during pregnancy in rats FASEB Journal 7 566-571

Croxatto HB and Villalón M (1994) Oocyte transport. In Cambridge Reviews in Human Reproduction: The Oocyte pp 253-276 Eds JG Grudzinskas, T Chard, JL Simpson and J Yovich. Cambridge University Press, Cambridge

Croxatto HB, Ortiz ME, Forcelledo ML, Fuentealba B, Noé G, Moore G, Morán F and Cárdenas H (1991) Hormonal control of ovum transport through the rat oviduct Archivos de Biología y Medicina Experimental 24 403-410

Dickmann Z and Noyes R (1960) The fate of ova transferred into the uterus of the rat Journal of Reproduction and Fertility 1 197-212

Ekerhovd E, Brännström M, Alexandersson M and Norström, A (1997) Evidence for nitric oxide mediation of contractile activity in isolated strips of the human Fallopian tube Human Reproduction 12 301-305

Fuentealba B, Nieto M and Croxatto H (1988) Progesterone abbreviates the nuclear retention of oestrogen receptor in the rat oviduct and counteracts oestrogen action on ovum transport Biology of Reproduction 38 63-69

Halbert SA, Tam PY and Blandau RJ (1976) Ova transport in the rabbit oviduct. The roles of the cilia and muscle Science 191 1052-1053

Hermoso M, Villalón M, Bavister BD and Magness RR (1996) Preimplantation hamster embryos produce prostaglandin $\mathrm{E}_{2}$ and platelet activating factor Biology of Reproduction 5480

Hermoso M, Sáez JC and Villalón M (1997) Identification of gap junctions in the oviduct and regualtion of connexins during development and by sexual hormones European Journal of Cell Biology 74 1-9

Moore GD and Croxatto HB (1988a) Synthetic microspheres transferred to the rat oviduct on day 1 of pregnancy mimic the transport of native ova Journal of Reproduction and Fertility 82 735-742

Moore GD and Croxatto HB (1988b) Effects of delayed transfer and treatment with oestrogen on the transport of microspheres by the rat oviduct Journal of Reproduction and Fertility $\mathbf{8 3} 795-802$

Nathan C (1992) Nitric oxide as a secretory product of mammalian cells FASEB Journal 6 3051-3064

Ortiz ME, Villalón M and Croxatto HB (1979) Ovum transport and fertility following postovulatory treatment with estradiol in rats Biology of Reproduction 21 1163-1167

Ortiz ME, Noe G, Bastias G, Darrigrande O and Croxatto H (1994) Increased sensitivity and accumulation of estradiol in the rat oviduct during early pregnancy Biological Research 27 57-61
Perez Martinez S, Franchi AM, Suburo A, Herrero B, Goin JM, Hiroshi O and Gimeno MAF (1997) There are several isoforms of nitric oxide synthase (NOS) on rat oviduct Biocell 21 215-223

Perez Martinez S, Franchi AM, Viggiano JM, Herrero B and Gimeno MAF (1998) Effect of prostaglandin $\mathrm{F}_{2 \alpha}\left(\mathrm{PGF}_{2 \alpha}\right)$ on oviductal nitric oxide synthase (NOS) activity: possible role of endogenous $\mathrm{NO}$ on $\mathrm{PGF}_{2 \alpha}$-induced contractions in rat oviduct Prostaglandins and Other Lipids Mediators 56 155-166

Portnow J, Talo A and Hodson BJ (1977) A random wall model of ovum transport Bulletin of Mathematics and Biology 39349

Rosselli M, Imthum B, Macas E, Keller PJ and Dubey RK (1994) Endogenous nitric oxide modulates endothelin 1 induced contraction of bovine oviduct Biochemical and Biophysical Research Communications 201 143-148

Rosselli M, Keller PJ and Dubey RK (1998) Role of nitric oxide in the biology, physiology and pathophysiology of reproduction Human Reproduction 4 3-24

Shukovski L and Tsafriri A (1994) The involvement of nitric oxide in the ovulatory process in the rat Endocrinology 135 2287-2290

Sokal RR and Rohlf FJ (1981) The normal probability distribution. In Biometry: Principles and Statistic Methods in Biological Research p. 98. WH Freeman and Company, New York

Sueoka K, Dharmarajan AM, Miyazaki T, Atlas SJ and Wallach EE (1989) In vivo and in vitro determination of components of rabbits early factors Journal of Reproduction and Fertility 87 47-53

Talo A (1991) How the myosalpinx works in gamete and embryo transport Archivos de Biología y Medicina Experimental 24 361-375

Van Voorhis BJ, Dunn MS, Snyder GD and Weiner CP (1994) Nitric oxide: an autocrine regulator of human granulosa-luteal cell steroidogenesis Endocrinology 135 1799-1806

Verdugo P and Villalón M (1993) Functional anatomy of the Fallopian tube. In Infertility Male and Female pp 53-84 Eds V Insler and B Lunenfeld. Churchill Livingstone, London

Verdugo P, Blandau RJ, Tam PY and Halbert SA (1976) Stochastic elements in the development on deterministic models of ova transport. In Ovum Transport and Fertility Regulation pp 126-137 Eds MJK Harper, CJ Pauerstein, CE Adams, EM Coutinho, HB Croxatto and DM Patón. Scriptor, Copenhagen

Viggiano M, Zicari JL, Gimeno AL and Gimeno MAF (1990) Influence of ova within rat oviducts on spontaneous motility and on prostaglandins production Prostaglandins Leukotrienes and Essential Fatty Acids 41 13-17

Villalón M, Verdugo P, Boling JL and Blandau RJ (1991) The transport of cumulus egg masses through the ampullae of the oviducts in the pigtailed Macaca nemestrina. Archivos de Biología y Medicina Experimental 24 385-391

Villalón M, Hermoso M, Budinich M, Aguilera J and Sáez JC (1997) Regulation of smooth muscle activity and gap junction by sexual hormones in the oviduct. In From Ion Channels to Cell-to-Cell Conversations pp 459-468 Eds Latorre and Sáez. Plenum Press, New York

Woodruff JD and Pauerstein CJ (1969) The Fallopian Tube Williams and Wilkins, Baltimore

Yallampalli C, Garfield RE and Byam-Smith M (1993) Nitric oxide inhibits uterine contractility during pregnancy but not during delivery Endocrinology 133 1899-1902

Yallampalli C, Byam-Smith M, Nelson SO and Garfield RE (1994a) Steroid hormones modulate the production of nitric oxide and cGMP in the rat uterus Endocrinology 134 1971-1974

Yallampalli C, Izumi H, Byam-Smith M and Garfield RE (1994b) An Larginine:nitric oxide-cGMP system exists in the uterus and inhibits contractility during pregnancy American Journal of Obstetrics and Gynecology 170 175-185 